SILVA, K. A. da; MASTRELlA-DE-ANDRADE, M.; PEREIRA FILHO, C. A. A formação de professores de línguas: políticas, projetos e parcerias. Campinas, SP: Pontes Editores, 2015.

\title{
A FORMAÇÃO DE PROFESSORES DE LÍNGUAS: POLÍTICAS, PROJETOS E PARCERIAS
}

Resenhado por: Katia Barbara Gottardi MULON ${ }^{1}$

Objeto de contínua investigação por parte de pesquisadores da Linguística Aplicada, a formação de professores de línguas configura-se como um dos temas centrais do campo, com vasta produção divulgada tanto em revistas e congressos, quanto em livros, como os recentemente editados: Novas tendências no ensino/aprendizagem de línguas românicas e na formação de professores, organizado por Olga Alejandra Mordente e Roberta Ferroni, Reflexões na linguística aplicada - a formação de professores de línguas e a prática em sala de aula: caminhos e expectativas, organizado por Lúcia Rottava, Patrícia da S. Campelo Costa Barcellos, Eduardo de Oliveira Dutra e Isis da Costa Pinho, Linguagem e educação: ensino-aprendizagem e formação de professores de línguas, organizado por Ana Paula Marques Beato-Canato e Gladys Quevedo-Camargo, Formação de professores de línguas em múltiplos contextos: construindo pontes de saberes e agenciamentos, organizado por Cláudia Maria Bokel Reis e William Soares dos Santos e Apendicite formativa nos cursos de letras: reflexões sobre a formação do professor de inglês, de autoria de Alessandra da Silva Quadros-Zamboni - todos publicados em 2015.

Neste contexto insere-se também o objeto desta resenha: A formação de professores de línguas: políticas, projetos e parcerias, organizada por Kleber Aparecido da Silva (UnB), Mariana Mastrella-de-Andrade (UnB) e Cesário Pereira Filho (UnB). Desde o prefácio escrito por Vilson Leffa (UCPel), a temática deste livro se apresenta numa perspectiva multidimensional: para condensar sua visão sobre o tema do livro, Leffa empresta a noção de dicotomia saussuriana e propõe quatro dicotomias associadas à formação do professor de línguas: sonho/realidade, protagonista/coadjuvante, indivíduo/estrutura e tempo/espaço. Essa perspectiva multidimensional permeia toda a coletânea prefaciada, composta por três partes que abordam i) políticas de formação de professores de línguas, ii) formação de professores e

\footnotetext{
${ }^{1}$ Mestranda em Estudos Linguísticos pela Universidade Federal do Paraná.
} 
pedagogia crítica e iii) projetos e parcerias em escolas públicas. Para Leffa, essas quatro dicotomias por ele propostas poderiam encaminhar a uma quinta: teoria/prática, que permeia grande parte dos artigos do livro, fundamentados essencialmente na teoria crítica.

Posteriormente, na apresentação da obra, os organizadores informam ao leitor que os artigos são produto de trabalhos apresentados durante o IV Congresso LatinoAmericano de Formação de Professores de Línguas (CLAFPL), promovido pela Universidade de Brasília em 2013, evento que abriu espaço para a reflexão sobre três aspectos de extrema importância para a educação: políticas, projetos e parcerias. Ancorados na Linguística Aplicada, os organizadores desenvolvem pesquisas nas áreas de ensino-aprendizagem de línguas, aquisição de língua estrangeira e formação de professores. Tanto Leffa quanto Silva, Mastrella-de-Andrade e Pereira Filho recorrem a Paulo Freire $(1968,1996)$ para i) enfatizar a relação teoria/prática (práxis) enquanto ação criadora e modificadora da realidade e ii) ressaltar a representatividade dos trabalhos selecionados para compor o livro, que apresentam possibilidades de atuação no campo de formação de professores de línguas, já que a vida social é inacabada e, desta forma, passível de modificação.

Iniciando a apreciação dos artigos em si, a primeira parte do livro, intitulada Políticas de formação de professores, é composta por quatro capítulos que versam sobre: a identidade do professor; o papel dos formadores de docentes na implementação da política linguística de inglês na Colômbia; a pesquisa, a capacitação e o desenvolvimento dos profissionais em inglês (estes dois últimos escritos em espanhol) e a pesquisa em formação de professores de línguas no Brasil.

Em Professor: uma identidade não herdada, artigo fruto da conferência de abertura do IV CLAFPL e capítulo de abertura do livro, Hilário Bohn (UCPel) discute $\mathrm{a}(\mathrm{s})$ identidade(s) de professor, em especial a(s) do professor de línguas, à luz de sua instabilidade constitutiva, ou seja, ao mesmo tempo em que há uma coerência com traços históricos, também persiste uma singularidade resultante das transformações e dos contextos de vivência. Para essa discussão, Bohn apoia-se nos Estudos Culturais e na Sociologia e, apesar da vasta experiência no campo da educação, adota uma postura de distanciamento do objeto, argumentando que somente assim se pode adentrar a complexidade constitutiva da identidade profissional de professor. Recorrendo à tipificação de Elias e Scotson (2000), que separam os membros de uma comunidade em estabelecidos e outsiders, Bohn enfatiza a ausência de voz tanto de professores quanto de 
alunos nas decisões relacionadas à educação no Brasil, caracterizando o professor como um outsider no debate nacional sobre ensino e aprendizagem. Outra dimensão abordada pelo autor refere-se à "identificação" do professor pela mídia. Segundo Bohn, há um amplo debate nacional sobre a educação brasileira nos seus mais variados aspectos, com a imprensa sinalizando para a substituição de humanos por máquinas e softwares, por exemplo, quando trata do ensino à distância ou da disponibilização de materiais didáticos online, o que gera aumento de produtividade e lucro. Assim, o professor precisa se inserir neste debate sobre esse novo modo de "fazer escola" para se integrar no grupo dos "estabelecidos". Para concluir, o autor se propõe a criar uma imagem de professor para além daquilo que se possa imaginar e sugere aos professores uma radicalização nos moldes expressos por Freire (1987) em Pedagogia do Oprimido. Segue afirmando que, para que se possa expandir as discussões sobre a(s) identidade(s) de professor, é imprescindível reintegrar as vozes de professor e aluno, pois são eles os principais atores da educação. Neste sentido, o autor reforça as significativas contribuições de Antonieta Celani e outros linguistas aplicados que atuam no ensino de línguas estrangeiras ao dar voz aos professores em suas pesquisas, estimulando-os a refletir sobre suas práticas.

No segundo artigo, ¿Nos han desplazado? ¿O hemos claudicado? El debilitado papel crítico de universidades públicas y los formadores docentes en la implementación de la política educativa lingüística del inglés em Colombia, Adriana González M. (Universidade de Antioquia) propõe uma reflexão a respeito do papel inicial e posterior dos formadores de professores na discussão sobre a implementação da educação bilíngue, através do Programa Nacional do Bilinguismo (PNB), com a promoção do ensino de inglês como língua complementar desde a educação primária nas escolas da Colômbia a partir de 2006, considerando que estas políticas educacionais estão muito distantes da realidades dos variados contextos educacionais do país. Será que os formadores e as universidades públicas foram excluídos da discussão ou têm desistido dela com o passar do tempo? São discutidos fatores que apontam tanto para a exclusão quanto para a desistência. Ao responder a estas questões, a autora apresenta um retrospecto das políticas de promoção do ensino de inglês na Colômbia, comenta os trabalhos acadêmicos publicados desde a implementação do PNB e indica exemplos de ação de atores não pertencentes ao âmbito educacional na formulação e desenvolvimento destes programas para a promoção do ensino da língua inglesa. Por fim, González sugere algumas ações 
com o intuito de contribuir para a análise da formação inicial e continuada de professores de inglês na América Latina.

Já no exemplo trazido da Costa Rica, no capítulo intitulado La investigación, la capacitación y desarrollo de los profesionales en inglés: un esfuerzo compartido, Allen Quezada Pacheco (Universidade de Costa Rica) traça um panorama dos esforços implementados por diferentes instituições governamentais e não-governamentais para formar e capacitar professores de inglês de forma a atender às metas do Plano Nacional de Inglês, que visa a dotar a população com as competências linguísticas da língua inglesa, de forma a permitir um maior desenvolvimento pessoal e profissional, aumentando a possibilidade de acesso a empregos de maior remuneração. A autora apresenta, ainda, estudos de professores-pesquisadores sobre o processo de ensino/aprendizagem de inglês, que buscam tanto fornecer novas ferramentas aos professores, quanto explicitar o impacto destas pesquisas nas políticas educacionais da Costa Rica.

Encerrando a primeira parte e voltando ao foco nacional, Deise Prina Dutra (UFMG) apresenta no capítulo seguinte Os passos da pesquisa em formação de professores de línguas no Brasil, título de seu artigo. Com o objetivo de discutir o papel das pesquisas na formação destes professores e tendo como base os trabalhos do IV CLAFPL, a autora aborda as diversas dimensões das referidas pesquisas: instituições, tipos, assuntos, divulgação, impacto, apoio governamental e redes de pesquisadores. No que se refere aos temas pesquisados, por exemplo, a autora ressalta a concentração de estudos relacionados às dificuldades de ensino/aprendizagem que carecem, porém, de uma análise quanto a outros fatores relevantes, como aspectos relacionados à formação de professores. Pensando no fomento de ações conjuntas, Dutra encerra seu artigo propondo a organização de uma rede latino-americana de pesquisa sobre formação de professores de línguas como forma de contribuir com iniciativas que busquem melhor construir a ponte entre teoria e prática.

A segunda parte do livro, denominada Formação de professores e pedagogia crítica, inicia com o artigo Gestão escolar em cadeias criativas: um processo para transformações escolares, de Fernanda Liberalli (PUC/SP) e de Suzete Borelli e Maria Emília de Lima (Secretaria Municipal de Educação/São Paulo), que discute como o conceito de gestão foi desenvolvido pela Secretaria de Educação da Cidade de São Paulo a partir da implementação do Projeto de Gestão em Cadeias Criativas em 2011. Baseado 
na Teoria da Atividade Sócio-Histórico-Cultural de Vygotsky (1934), o projeto, segundo as autoras, apresentou duas contribuições importantes: a construção de significados coletivos para o conceito de gestão e o planejamento de gestão para 2012 para escolas de Ensino Fundamental e Médio, que são objetos de análise aprofundada no desenvolvimento do artigo.

Já o capítulo Conhecer como reconhecer': estudos na formação crítica de professoras/es de língua estrangeira, de autoria de Rosane Rocha Pessoa (UFG), traça uma relação entre o modelo de pesquisa emergente a que Santos (1988, p. 37) chama de "paradigma de um conhecimento prudente para uma vida decente" e a Linguística Aplicada Crítica (PENNYCOOK, 2001) com o intuito de problematizar duas experiências de formação docente ao investigar dois estudos na área de Formação Crítica de Professoras/es conduzidos na UFG. Acreditando que estes estudos se pautem pelo tipo de conhecimento chamado por Santos (1999) "conhecimento-emancipação", a autora buscar responder se o processo de formação e o envolvimento de professoras/es é suficiente para que este conhecimento se concretize no trabalho docente.

Na terceira e última parte do livro, que trata de Projetos e parcerias em escolas públicas, o primeiro artigo Análise experiencial: um marco de referência para pesquisar o ensino em sala de aula de Laura Miccoli (UFMG) e Carolina Vianini (UFSJ) parte do perfil do professor de línguas prevalente na literatura (caracterizado pela deficiência tanto no que se refere a aspectos pedagógicos quanto à competência comunicativa) e defende que essa limitação não provém exclusivamente destes dois tópicos apontados na literatura: há outros elementos que podem ser trabalhados na formação inicial e continuada com vistas a uma preparação mais efetiva para a realidade de sala de aula. Neste contexto, as autoras retomam o conceito de experiência, buscando subsídios em Platão, Aristóteles, Hegel (1991) e Dewey (1938) e em contribuições de Maturana (2001) e Nuñez (1995), e argumentam que a pesquisa de base experimental pode fornecer dados relevantes sobre as interações em sala de aula, explicitando lacunas conceituais e contribuindo para uma caracterização mais abrangente do processo de ensino e aprendizagem. Miccoli e Vianini postulam que este tipo de investigação tem potencial para servir de referência para programas de educação inicial e continuada.

No capítulo seguinte, denominado Um projeto que deu certo: reflexão sobre a ação, Rosinda de Castro Guerra Ramos (PUC-SP) relata uma experiência de parceria e formação de professores de inglês na rede pública de São Paulo, realizada por meio do 
curso de especialização Práticas reflexivas e ensino-aprendizagem de inglês na escola pública, promovido conjuntamente pela Associação Cultura Inglesa São Paulo e pela PUC-SP. Além de descrever o programa e expor suas reflexões sobre formação docente, a autora apresenta os subsídios teóricos que nortearam o desenvolvimento e aplicação do curso de especialização: a reflexão crítica (KEMMIS, 1987; SCHÖN, 1987; NÓVOA, 1992) e o conceito de ação colaborativa (CELANI; COLLINS, 2003).

Em seguida, Maria do Socorro Oliveira (UFRN) apresenta, no capítulo intitulado Letramentos e políticas públicas: escola, família e comunidades, dois projetos que discutem a relevância da integração entre escola, família e comunidade, bem como discute as consequências dessa articulação para o desenvolvimento da leitura e escrita de alunos em condição de vulnerabilidade social. Estes dois projetos, O habitus de estudar: construtor de uma nova realidade na educação básica da Região Metropolitana de Natal e Letramentos e políticas públicas: escola vs. mundo contemporâneo, compõem ações de extensão de uma pesquisa etnográfica de natureza crítica que buscou promover um acercamento entre as comunidades científica e escolar, de forma a compreender o contexto da escola e, mais além, promover transformações na busca pela conscientização, fortalecimento e emancipação dos colaboradores. Para esta análise, Oliveira mobiliza uma orientação crítica de letramento e trabalha com a noção de projetos de letramento como dispositivos didáticos para ressignificar práticas de leitura e escrita e favorecer aprendizagens compartilhadas. Segundo a autora, "os projetos de letramento são vistos como organizações didáticas produtivas e inovadoras que possibilitaram o uso social e efetivo da leitura e da escrita" (p. 212). E conclui que políticas públicas de valorização do Letramento Familiar, em conjunto com o letramento escolar, são cruciais para dar sentido à leitura e à escrita e, mais além, à vida das pessoas.

O terceiro capítulo desta última parte trata da formação de professores de línguas para o uso de tecnologias. Intitulado A extensão da sala presencial para o Moodle ${ }^{2}$ : espaço de aprendizagem, reflexão e pesquisa nos cursos de Letras Francês e Espanhol da USP, o artigo de Heloísa Albuquerque Costa (USP) e Mônica Ferreira Mayrink (USP) apresenta os eixos que orientam a formação dos alunos nos referidos cursos de Letras da USP na plataforma Moodle, como exemplo de formação em ambientes virtuais de aprendizagem, e discute seu uso como complemento a cursos presenciais, relacionando reflexão, aprendizagem e pesquisa. Ao final da análise, as autoras avaliam que as ações

${ }^{2}$ Modular Object-Oriented Dynamic Learning Environment. 
pedagógicas e investigativas do aprendizado virtual associado ao presencial contribuíram significativamente para a formação inicial dos alunos, na medida em que ampliaram suas perspectivas através de experiências didáticas inovadoras. E finalizam citando como resultados mais importantes: o desenvolvimento de um olhar crítico com relação a novas modalidades pedagógicas, a construção de um espaço de reflexão e a adoção, por parte dos alunos, de um papel mais mediador no processo de aprendizagem, entre outros.

Avançando para o penúltimo capítulo desta terceira parte, as autoras de Linguagem, conhecimento e formação: teorias e práticas de formação continuada de docentes vivenciadas/desenvolvidas no contexto público de ensino estadual de Sinop/MT, Leandra Ines Seganfredo Santos (UNEMAT) e Rosinda de Castro Guerra Ramos (PUC/SP), nos situam na atual conjuntura brasileira de formação docente com base em uma pesquisa da Fundação Victor Civita, que retrata uma formação inicial reconhecidamente precária e uma formação continuada que carece de políticas públicas (FUNDAÇÂO VICTOR CIVITA, 2011). As autoras prosseguem informando que, no relatório desta pesquisa, as ações de políticas públicas de formação continuada do estado do Mato Grosso são avaliadas como inovadoras e apontadas como exemplos positivos. Neste contexto, Santos e Ramos buscaram, em seu artigo, descrever e discutir teorias e práticas que orientam alguns destes projetos, especificamente os programas de formação continuada desenvolvidos na rede estadual da cidade de Sinop/MT, decorrente da parceria entre o Centro de Formação e Atualização dos Profissionais da Educação Básica (CEFAPRO), a Universidade do Estado de Mato Grosso (UNEMAT) e a Pontifícia Universidade Católica de São Paulo (PUC-SP). Para tanto, discutiram temas como: as orientações teóricas e práticas dos profissionais desta rede estadual de ensino, a identidade dos professores formadores destes programas e como se deu o trabalho colaborativoreflexivo entre as Universidades e os professores-formadores do CEFAPRO. Ainda, desenvolveram uma (re)leitura das concepções teóricas que direcionam a prática com base nos seguintes documentos: Orientações Curriculares para a Educação Básica (2010a) e Orientações Curriculares para a Área de Linguagens (2010b) e, também, descreveram as políticas públicas de formação continuada no estado. Após essa análise, as autoras concluíram que os programas de formação continuada devem atender tanto às demandas gerais sobre educação e formação docente, quanto às especificidades de áreas/disciplinas e que os profissionais devem se apropriar das oportunidades oferecidas pelas políticas públicas para formarem-se na mudança e para a mudança. 
No artigo que encerra o livro, Momentos e espaços formativos para a docência: impactos do PIBID para o desenvolvimento da prática reflexiva de professores de línguas, as autoras Maria Cristina Reckziegel Guedes Evangelista (UNESP), Isadora Valencise Gregolin (UNESP), Cibele Cecílio de Faria Rozenfeld (UFSCar) e Nildicéia Aparecida Rocha (UNESP) discutem dois subprojetos PIBID desenvolvidos por graduandos e professores de duas universidades públicas do interior de São Paulo e por docentes de escolas públicas parceiras. Ao descreverem estes subprojetos, as autoras tecem considerações acerca dos subsídios teóricos que os norteiam, caracterizam seus espaços educacionais, pontuam possibilidades e dificuldades encontradas e, por fim, abordam algumas consequências da criação destes espaços para a promoção da prática reflexiva na formação inicial e continuada de professores. Após analisar portfolios, diários reflexivos, depoimentos e trabalhos apresentados pelos participantes do PIBID, as pesquisadoras concluíram que os espaços educacionais criados para os dois subprojetos investigados foram um diferencial na formação dos futuros docentes, na medida em que permitiram socializar saberes e experiências entre seus participantes e construir um embasamento profissional partilhado, contribuindo para sua construção como profissionais reflexivos. Citando Schön (2007), as pesquisadoras concluem que "pode-se afirmar que os participantes dos dois grupos PIBID passaram a 'compartilhar convenções de ação que incluem meios, ferramentas e linguagens distintivas', as quais constituem 'um corpo de conhecimento profissional explícito e organizado mais ou menos sistematicamente"”.

Ao longo de seus 12 capítulos e 269 páginas, o leitor encontrará artigos que apresentam tanto uma prevalência da orientação crítica, conforme apontado por Leffa no prefácio, quanto diversas referências à abordagem reflexiva de formação profissional.

Na perspectiva teórica crítica, há um compromisso com a justiça social no sentido de explicitar relações de desigualdade e promover mudanças. De acordo com James W. Tollefson (2006), pesquisador na área de linguística aplicada e políticas linguísticas, a teoria crítica "geralmente investiga processos através dos quais a desigualdade social é produzida e mantida, bem como a dificuldade de se reduzir essa desigualdade para trazer maiores formas de justiça social” (TOLLEFSON, 2006, p. 44). O linguista prossegue afirmando que, assim, a teoria crítica tem um caráter prático, já que procura "explicitar sistemas de exploração, especialmente os acobertados por ideologias, e encontrar formas superá-los" (TOLLEFSON, 2006, p. 44). 
Conforme mencionado anteriormente, é relevante observar, também, a orientação para a prática reflexiva da maioria dos seis artigos que compõem a terceira e última parte da obra, os quais retomam principalmente Dewey (1938) e Schön (1987, 1990, 1992, 2007). A abordagem reflexiva de formação leva o profissional a refletir sobre suas crenças, seus entendimentos sobre ensinar e aprender, ou seja, o professor se constrói enquanto pesquisador da própria prática. Em uma releitura de Dewey e do pensamento reflexivo, Rodgers (2002), esclarece que a reflexão não é um fim em si mesmo, mas uma ferramenta utilizada na transformação de experiência bruta em teoria, num processo espiral repetitivo que leva da teoria à prática e vice-versa. Segundo Schön (1992), as tradições de prática reflexiva "implicam um tipo de aprender fazendo, em que os alunos começam a praticar, juntamente com os que estão em idêntica situação, mesmo antes de compreenderem racionalmente o que estão a fazer".

Assim, este livro, de interesse para professores e pesquisadores de ensino/aprendizagem de línguas, professores-formadores, pesquisadores e legisladores no campo de políticas linguísticas, oferece uma importante contribuição para os estudos da formação de professores de línguas ao enfatizar a criticidade da articulação entre teoria e prática na formação docente e motivar para a pesquisa de práxis transformadoras com os exemplos de políticas, projetos e parcerias investigados na obra.

\section{Referências bibliográficas}

CELANI, M. A. A.; COLLINS, H. Formação contínua de professores em contexto presencial e à distância: respondendo aos desafios. In: BARBARA, L. RAMOS, R. C. G. (Orgs.). Reflexão e ações no ensino-aprendizagem de línguas. Campinas: Mercado das Letras, 2003. pp. 69-105.

DEWEY, J. Experience and education. New York: Touchstone, 1938.

FUNDAÇÃO VICTOR CIVITA. Estudos e pesquisas educacionais. Relatório Final. Formação continuada de professores: uma análise das modalidades e das práticas em estados e municípios brasileiros. Junho 2011. Disponível em: http://www.fvc.org.br/pdf/relatorio-formacao-continuada.pdf. Acesso em: 27/06/2012.

FREIRE, P. Pedagogia do oprimido. Manuscrito em português de $1968.17^{\mathrm{a}}$ ed. Rio de Janeiro: Paz e Terra, 1987.

Pedagogia da autonomia: saberes necessários à prática educativa. São Paulo:

Paz e Terra, 1996 
HEGEL, G.W.F. Fenomenología del espíritu. México: Fondo de Cultura Económica, 1991.

KEMMIS, S. Critical reflection. In: WIDEEN, M. F.; ANDREWS, I. (Eds). Staff development for school improvement. New York: The Elmer Press, 1987. pp.73-90.

MATURANA, H. Biologia do conhecer e epistemologia. In: MAGRO, C.; PAREDES, V. (Orgs). Cognição, ciência e vida cotidiana. Belo Horizonte: UFMG, 2001.pp. 19124.

MATO GROSSO. Orientações Curriculares. Concepções para a Educação Básica. SEDUC/MT. Cuiabá, MT, 2010a.

MATO GROSSO. Orientações Curriculares. Área de Linguagens: Educação Básica. SEDUC/MT. Cuiabá, MT, 2010b.

NÓVOA, A. Os professores e sua formação. Lisboa: Publicações Dom Quixote, 1992.

PENNYCOOK, A. Critical Applied Linguistics: a critical introduction. New Jersey: Lawrence Erlbaum Associates, 2001.

RODGERS, C. Defining reflection: another look at John Dewey and reflective thinking. Teachers College Record, v. 104, n. 4, pp. 842-866,June 2002.

SANTOS, B. de S. Um discurso sobre as ciências na transição para uma ciência pósmoderna. Estudos Avançados, v. 2, n. 2, pp. 46-71, maio/ago, 1988. Disponível em: http://dx.doi.org/10.1590/S0103-40141988000200007. Acesso em: 06/02/2013.

Por que é tão difícil construir uma teoria crítica? Revista Crítica de Ciências Sociais, n. 54, p. 197-215,1999.

SCHÖN, D. A. Educating the reflective practitioner: toward a new design for teaching and learning in the professions. San Francisco: Jossey-Bass Publishers: 1987.

Formar professores como profissionais reflexivos. In: NÓVOA, A. Os professores e a sua formação. Lisboa: Dom Quixote, 1992. pp.77-91.

Educando o profissional reflexivo: um novo design para o ensino e a aprendizagem. Trad. Roberto Cataldo Costa. Porto Alegre: Artmed, 2007.

TOLLEFSON, J. W. Critical theory in language policy. In: RICENTO, Thomas. An introduction to language policy: theory and method. Malden, MA, USA: Blackwell Publishers, 2006.pp. 42-55. 